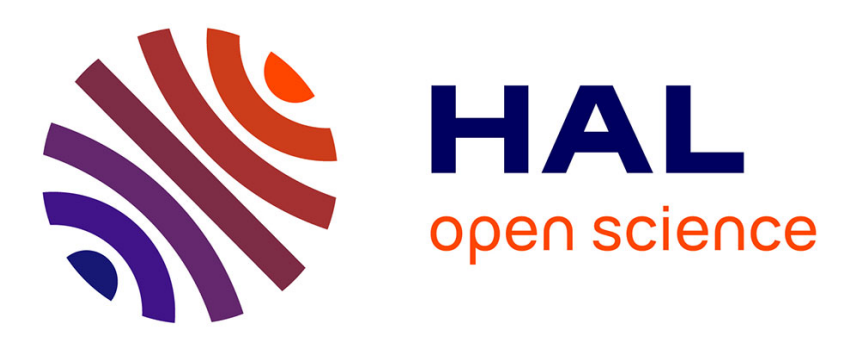

\title{
Materials for filtering and frequency control in the next generations of mobile communication systems
}

\author{
J. Détaint, J. Schwartzel
}

\section{To cite this version:}

J. Détaint, J. Schwartzel. Materials for filtering and frequency control in the next generations of mobile communication systems. Journal de Physique IV Proceedings, 1994, 04 (C2), pp.C2-93-C2106. 10.1051/jp4:1994212. jpa-00252480

\section{HAL Id: jpa-00252480 https://hal.science/jpa-00252480}

Submitted on 1 Jan 1994

HAL is a multi-disciplinary open access archive for the deposit and dissemination of scientific research documents, whether they are published or not. The documents may come from teaching and research institutions in France or abroad, or from public or private research centers.
L'archive ouverte pluridisciplinaire HAL, est destinée au dépôt et à la diffusion de documents scientifiques de niveau recherche, publiés ou non, émanant des établissements d'enseignement et de recherche français ou étrangers, des laboratoires publics ou privés. 


\title{
Materials for filtering and frequency control in the next generations of mobile communication systems
}

\author{
J. DÉTAINT and J. SCHWARTZELL
}

France Telecom, CNET/PAB, Laboratoire de Bagneux, 196 Av. H. Ravera, BP. 107, 92225 Bagneux, France

\begin{abstract}
A very large development of the mobile radiocommunications is expected to occur in the 15 next years. In the introduction, the most important among the present and future systems are listed and their main characteristics are briefly indicated. The case of the Universal Mobile Telecommunication System (UMTS) presently studied in the European community to enter service in the beginning of the 2000's is particularly discussed since, it is now, the most ambitious project in this field. The equipments of the future numerical radiocommunication systems will include a large number of piezo-electric devices for filtering and frequency generation. New characteristics (higher frequencies, larger bandwidth, very reduced dimensions, etc...) will be required for these devices so that new developments will be necessary to find solutions to these requirements. It is believed, that the corresponding evolutions will be very significant of the main trends in piezo-electricity for the next ten years.

This paper review the UHF and VHF filtering technologies and the frequency generation techniques the most likely to be used in the future radiomobile systems. For each kind of devices (filters for either UHF or an intermediate frequency and frequency sources), we discuss the most probable requirements, the present state of the different technologies, the new advances required to develop highly miniaturized devices for the mobile equipments or high performances sub-assembly for the base stations. In most cases, it appears that the availability of new piezo-electric materials and the obtainment of better characteristics for the existing materials will be essential factors in the achievement of the required characteristics for these devices. The possibilities of integrating piezo-electric resonators or filters with the micro-electronics contributing to the same or to related functions is also discussed together with the interest of developing new thin film piezo-electric materials permitting this integration.
\end{abstract}

\section{INTRODUCTION:}

In the last 10 years, the market of voice mobile communications for professional or private use was principally covered by the analogy cellular systems serving essentially car radiotelephones. The need to use more efficiently the scarce frequency resource, those of an increasing need of communication from an increasing number of persons has led, in the recent years, to the definition and the implementation of new cellular systems using advanced access techniques, digitized voice transmission, numerical modulation and error correcting coding. In western Europe, this has led to the normalisation of an unique system, the GSM (Global System for Mobile communication) which has enter service in 1992. To increase further the spectral efficiency while responding to the new demand of personal miniaturized handheld terminals following the subscriber in all his displacements, the concept of microcellular systems was introduced. In Europe, the Digital Cellular System at $1800 \mathrm{MHz}$ (DCS1800) using essentially the same technical solution as GSM, was normalized; it will enter service in the next years. In the same time, the need of specialized systems for communications directly between airplanes and earth stations or between airplanes or ships and earth via satellites has appeared, and several are being implemented (TFTS, AMSS). The home cordless 
telephones are also evolving towards digital technology (CT2-CAI, DECT) while converging with other private and public personal short distance radiocommunication needs. Public point to point systems (Pointel, BiBop in France), are addressing the market of pedestrian communications in the centre of cities.

The study of a future system that will cover all the aspects of mobile and personal communications at the beginning of the next century was initiated by the European Community four years ago. This system named Universal Mobile Telecommunication System (UTMS), will include nearly all the services designed in the previous systems, plus a variety of new ones including broadband services. On figure 1 is given a representation of the coverage of the UMTS due to A.Charbonnier et al. [1].

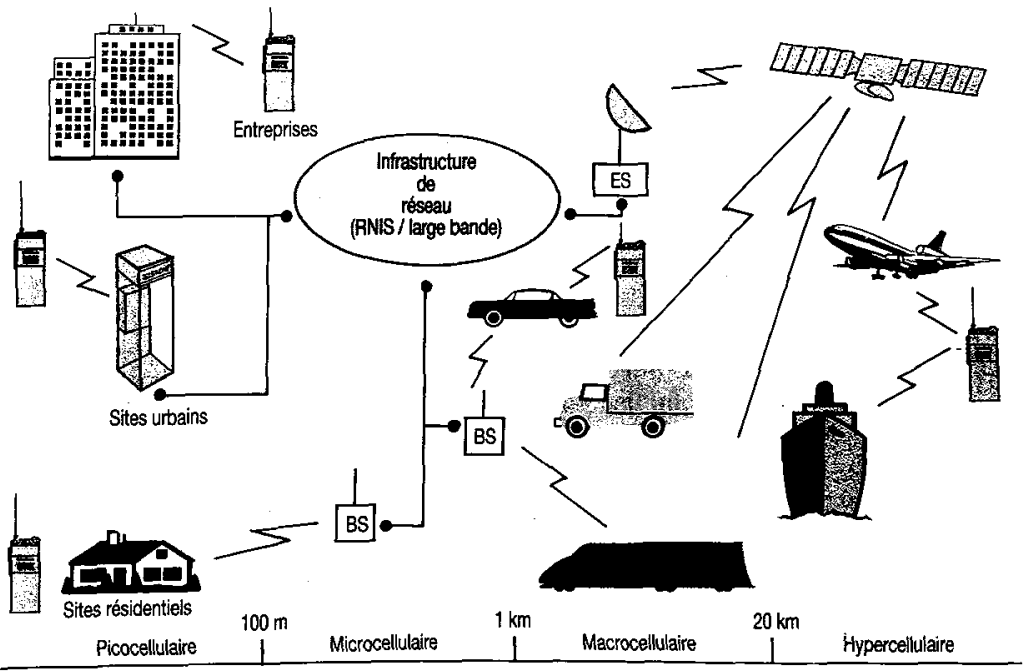

Figure 1: Coverage of the Universal Mobile Telecommunication System [1].

The personal terminals for this system will have to be extremely miniaturized (pocket size) and low cost. The existence of a wide range of types of terminals is expected. A large number of "stations" (interfaces between the "air" and the fixed networks), will also have to meet similar requirements for the size and the cost (particularly for pico or nano cells etc...). The studies made in the RACE projects have identified two possible implementations of the radio-interface differing principally by the access technique (TDMA or CDMA) that are being evaluated. In both cases, hypothesis concerning the design parameters of the radio-interface (baud rates, type of modulation, voice coding etc) were made.

The consequences of the probable choices on the requirements for the filters and the frequency generation devices will be discussed in the next paragraphs. The Word Administrative Radio Conference has in 1992 allocated frequency bands to the Future Public Land Mobile Telecommunication System; the UMTS is presently to be considered as the European project of implementation of the FPLMTS. In table 1 and figure 2, the main characteristics and the frequency allocations of the recent and future systems are indicated, more details can be found in references [1]\&[2].

Table 1: Principal recent or future public radiocommunication systems.

\begin{tabular}{rr}
\hline GSM (GLOBAL SYSTEM for MOBILE communication) & European 1992 \\
$890-915$ \& 935-960MHz TDMA/FDMA, GMSK, channel $200 \mathrm{kHz}=8 * 22.8 \mathrm{kbit} / \mathrm{s}$
\end{tabular}

DCS 1800 (Digital Cordless System at $1800 \mathrm{MHz}$ ) $1710-1785$ \& $1805-1880 \mathrm{MHz}$ same parameters as GSM

DECT (Digital European Cordless Telecommunications)
1880-1900 TDMA/FDMA, GMSK, channel 1728kHz=12*96kbit $/ \mathrm{s}$

UMTS (Universal Mobile Telecommunication System)

European projects

1885-2025 \& 2110-2200 TDMA or CDMA

opening 2002 ?

Under study (European Community RACE projects) 


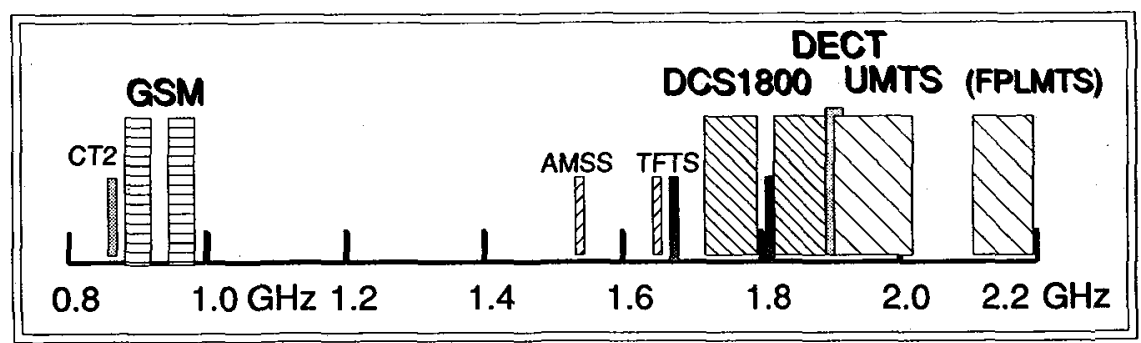

Figure 2: Frequency allocations for present and future digital radiocommunication systems.

\section{Filtering and frequency generation in the Radio sub-system of radiocommunication equipments.}

The typical architecture of the radio sub-system of present mobiles or base stations is represented on figure 3. We have chosen to represent the most usual options encountered in recent equipments (direct modulation and two intermediate frequencies in the receiver), other options are possible principally on these two later points. The antenna is connected to filters constituting most often a diplexer (otherwise the filters must be switched altematively). These UHF filters select the two sub-bands corresponding to the base to mobile and to the mobile to base traffic.

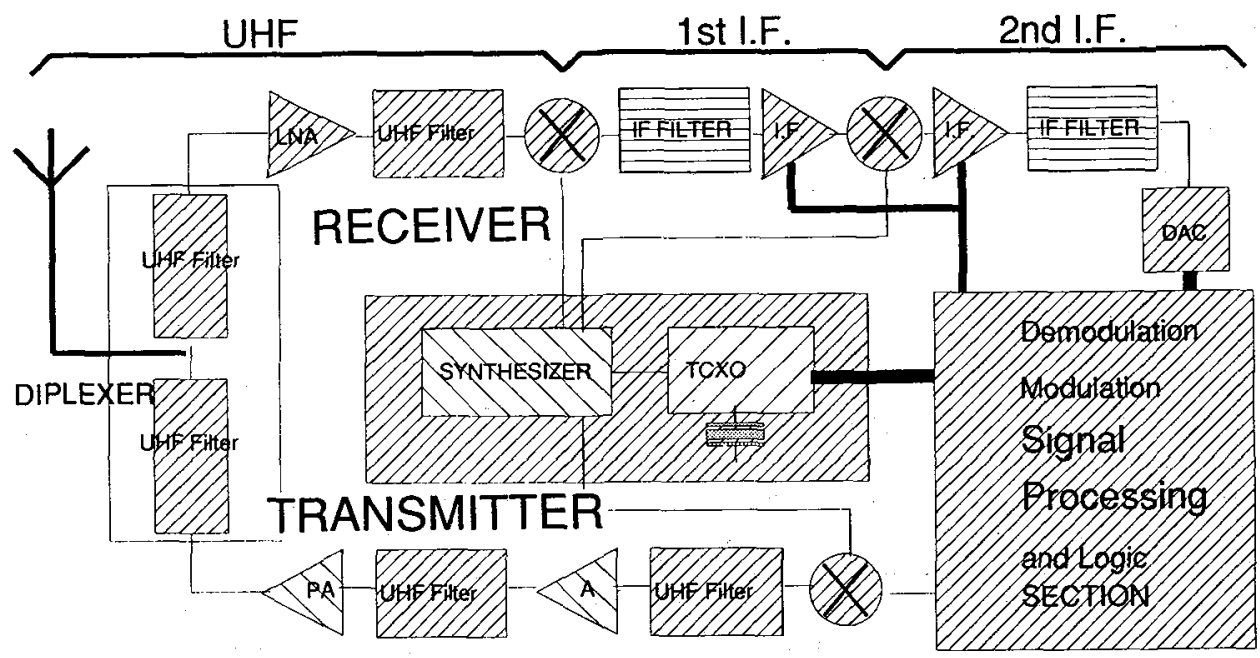

Figure 3: Typical architecture of the radio sub-system.

The receiver section includes then a low noise amplifier making a first amplification of the signal while minimizing the noise figure of the reception chain. Generally a post amplification filter is used after the LNA to complement the UHF selectivity and to remove the maximum of out-of band intermodulation products before the frequency transposition. After this one, an intermediate frequency filter selects the useful frequency "channel" which is shared by several mobiles (TDMA or CDMA). Eventually a second intermediate frequency with filtering is used to further complement the selectivity of the first one, and to limit the spectrum of the signal before the analog to digital conversion. In the figure, the case of a direct 2 nd IF to digital conversion is considered. The reference frequency for the synthesizer is generated by a crystal oscillator which is usually of the VCXO type in the mobiles and a high stability OCXO in the base stations. The transmitter section includes a post modulation UHF filter and generally a second filter after the amplification preceding the power amplifier. In many instances, the UHF voltage controlled oscillators included in the synthesizer make use of resonators of the same type as those existing in the filters, their high $Q$ factors allows to obtain interesting phase noise characteristics. 
No fundamental modifications of the basic principles of the UHF and IF architecture of the equipments are very likely to occur for the next generations. But, the use of techniques, such as space diversity or variable baud rate transmissions, that may increase notably the complexity of the radio sub-system by duplicating several functions, is very probable. Most probably, the radio sub-assembly will have to display a high flexibility (several configurations digitally chosen). For the filters, this can mean variable centre frequency or variable bandwidth numerically allocated.

As far as the market will grow, it will become more and more important to obtain enhanced performances (noise factor, intermodulation, phase noise etc..) of both the receiver and transmitter, since the possible number of subscribers within the frequency bands available is also dependant on several of these performances. The need to offer very small (pocket size) terminals having a much increased complexity will lead to research a important reduction of the volume of the different functions. This, in tum, will require important evolutions of the characteristics and technologies of the components.

All the active components of the radio sub-system will, most probably, be integrated in a very reduced number of integrated circuits (I.Cs). The characteristics of the filters and of the frequency generation devices are important factors in the overall performances; their number will most probably increase greatly in UMTS equipments. As a consequence of the integration of the electronics, they will become a major factor of the dimension of the radio sub-assembly. So that the challenge will be to improve their performances (insertion losses, selectivity, phase noise,...) while decreasing drastically their dimensions. Moreover, due to the use of higher ultra high frequencies and to the increase of the baud rates, the characteristics required for the filters and the frequency sources, will often be, quite different of those of existing devices, so that new solutions are to be found.

One can expect that the evolutions of the components required for the next generation of systems will also have noticeable impacts on those required for the future generations of equipments of the existing systems. In the next paragraph, we will review the most probable solutions and evolutions for the filters and the frequency generation devices.

\section{UHF FILTERS:}

The main functions of the UHF filters is to select the frequency bands in which the equipment can transmit or receive while attenuating the unwanted signals situated out of these bands.

\subsection{Antenna filters, diplexers for the UMTS.}

When transmission and reception occur on separate frequency bands the two UHF antenna filters are most often connected as a diplexer, even if there is no simultaneous 2 ways transmission. This result of the fact that fast $T / R$ switching is either difficult, costly or degrade somehow the performances, whereas using a diplexer does not add practically any additional complexity and cost. To constitute a diplexer, the filters must meet several requirements concerning essentially the input impedance, and the attenuation in the pass band of the other filter. For the UMTS, the T-R frequency separation could be of the order of $200 \mathrm{MHz}$ (or lower), while the bandwidth required could be of the order of $100 \mathrm{MHz}$, so that a T/R rejection of above $80 \mathrm{~dB}$ will be achieved using two 4 or 5 pole filters, this imply that the ultimate out of band rejection has to be maintained below this quantity, which is a quite demranding performance at $2 \mathrm{GHz}$. Reduced insertion losses in the pass-band will be searched for, since this quantity directly impacts the noise factor of the receiver and energy saving in the transmitter. A value near one $\mathrm{dB}$ seems to be a realistic objective. As mentioned previously, the size of the filters has to be very reduced from the present state of the art ( $\# 0.4 \mathrm{~cm} 3 /$ pole). These filters have to transmit or, to be submitted, to a noticeable power (depending of the type of equipment).

\subsection{Other UHF filters.}

The specifications for the other filters will most probably be quite similar, with probably somehow less stringent ultimate out-of-band rejections (60dB?), and insertion losses (2dB?). Again, very small dimensions will be required, but due the functions of this filters (see diagram of figure 3), the best solution can be to find a mean to co-integrate them with the corresponding electronics on silicon and gallium arsenide I.Cs.

\subsection{UHF Filters Technologies.}

Several types of filters exist for applications near two $\mathrm{GHz}$, few can present simultaneously reduced insertion losses and small dimensions. Many works were, in the recent years, devoted to improve the performances of the $800-900 \mathrm{MHz}$ UHF filters for the first generation of digital radiotelephones (GSM in Europe). The development of filters, presenting, at $2 \mathrm{GHz}$, better characteristics than the preceding ones, will require, at least, the same efforts. 
A tentative comparison of the different technologies is made on figure 4 , in the case of filters centered at 2 $\mathrm{GHz}$, having a bandwidth equal to $100 \mathrm{MHz}$, and a response equivalent to that of a 4 poles resonator filter. Four technologies allows reduced dimensions and insertion losses: the piezo-electric thin film resonators (TFR) filters, the surface acoustic waves (SAW) filters, the magnetostatic waves (MSW) filters and the coaxial dielectric resonator (DR) filters using quarter (or half wave) resonators. In figure 4 , we have indicated the present state of the art for these filters and our assumptions about what could be their characteristics at the service opening of the UMTS. Due to the very reduced insertion losses provided, the technology, using "full size" dielectric resonators enclosed in metal cavities, can also be of interest for some applications in base station equipments.

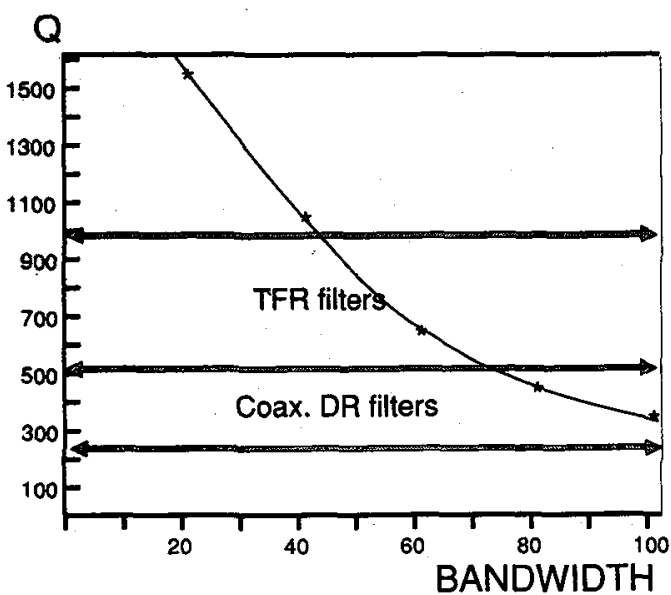

Figure 5: $\mathrm{Q}$ factor required for a $2 \mathrm{~dB}$ insertion loss (4 poles filter at $2 \mathrm{GHz}$ )

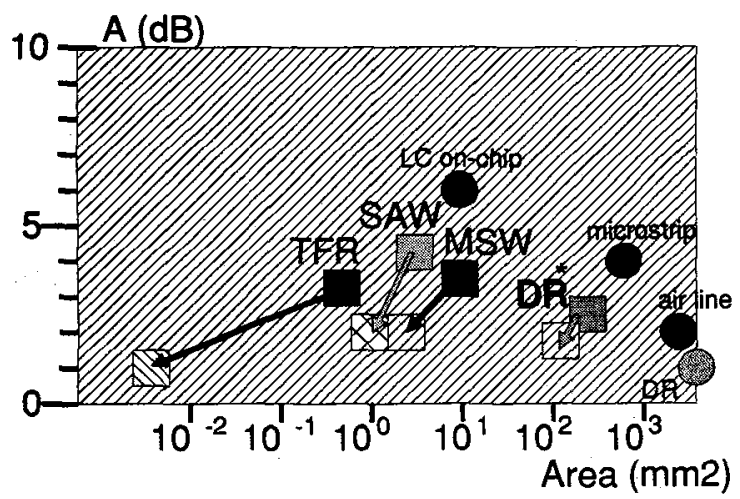

Figure 4: UHF filters at $2 \mathrm{GHz}$

An important remark to be made about figure 4 , is the fact that, except for the latter one, no type of filters approaches now, even from far, the desirable insertion losses. Now, the most common UHF filters, for mobile applications $(800-900 \mathrm{MHz})$, are the coaxial dielectric resonators filters. The present values of the $Q$ factors of the resonators (300-400 for the quarter wave ones) lead to insertion losses above $2 \mathrm{~dB}$ for a bandwidth of $100 \mathrm{MHz}$ at $2 \mathrm{GHz}$. This limitation result much more from the geometry of the resonators and from the dissipation in the silver metallizations than from the dielectric material used. The use of larger resonators (quarter or half wave) and the advent of room temperature superconductors are among the possible solutions to improve their quality. Much higher Q factors (800) were observed at $1.8 \mathrm{GHz}$ for the thin film resonators. On figure 5 , we have represented, as a function of the bandwidth, the $Q$ factors necessary for the resonators to obtain a $2 \mathrm{~dB}$ insertion loss $(4$ poles filters at $2 \mathrm{GHZ}$ with no losses in the other elements of the filters).

\subsection{Thin film resonator filters.}

As indicated in figure 4, this promising technique permits to obtain extremely reduced dimensions for the filters. The filter are constituted of half wave resonators made with a piezo-electric thin film electroded with two metal films, and of coupling elements (inductance and/or capacitance). The piezo-electric thin films can be either mono-crystalline ones or constituted of textured highly oriented films. Interesting insertion losses $(1.1 \mathrm{~dB}$ at $1 \mathrm{GHz}$ and 3.5 at $1.8 \mathrm{GHz}$ [3] were already demonstrated together with important out of band rejections.

The resonators are obtained using various thin film deposition methods, on different substrates; the feasibility of their integration with silicon or gallium arsenide circuit has already been demonstrated [4][5]. It was also demonstrated that they can withstands power levels in excess to 0.4 Watt. This value can be increased either by the choice of the material or by using different filter architectures. 
The resonators have extremely reduced lateral Table 2: Properties of materials for applications to thin dimensions (of the order of $5 \times 5$ to $20 \times 20 \mu \mathrm{m}$ at 2 films resonators filters.

$\mathrm{GHz}$ [6], their thickness is governed by the velocity of the acoustic waves, and is of the order of 1 to 2 microns at this frequency. The material mostly used now in such filters are zinc oxide films or aluminium nitride films. The most important properties of these materials are listed in table 2, where we have also indicated the properties of the most promising new thin film materials now being studied. In this table we can observe that the $\mathrm{ZnO}$ and AIN have medium coupling coefficients. This leads, for a $5 \%$ fractional bandwidth, (100MHz at $2 \mathrm{GHz})$, to the need to use inductances in the filter to compensate the static capacitance of the resonators. This, in tum contribute to have much greater insertion losses and surface, than what could be obtained without these inductances. With materials having a much higher coupling coefficient, these inductances can be suppressed. The foreseen improvements of the characteristics of thin film resonators filters, from the present state of the art, indicated on figure 4 , takes this fact into account.

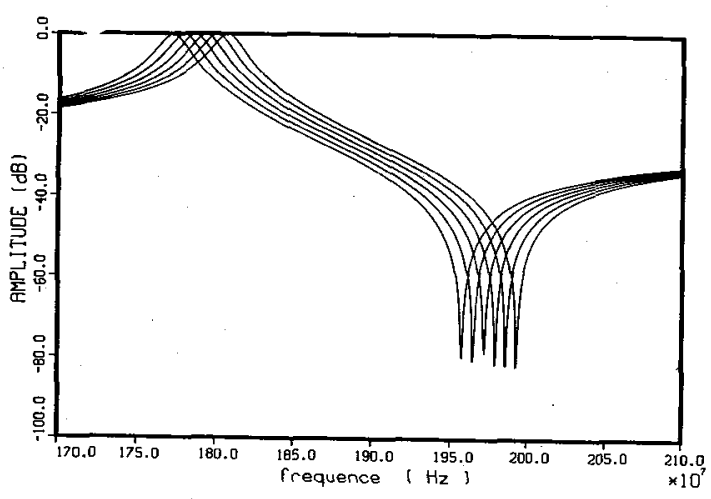

Other major advantages of the new materials are relative to their much better temperature coefficients $\left(10 . \mathrm{pmm} /{ }^{\circ} \mathrm{C}\right.$ is probably the maximal acceptable value), and to their much reduced acoustic losses. Most of them can be deposited using a new low temperature process, (the sol-gel technique [7]) giving highly oriented films and presenting many advantages such as a better compatibility with I.C. integration, and a lower cost than when using vacuum deposition methods.

On figure 6 , the computed electrical responses of resonators made using a thin layer of lithium tantalate and aluminium electrodes are displayed. The piezo-electric layer has a thickness of $1 \mu \mathrm{m}$, one electrode $\left(10^{*} 10 \mu \mathrm{m}\right)$ is $.1 \mu \mathrm{m}$ thick while the thickness of the second electrode is varied from .05 to $.1 \mu \mathrm{m}$. One can observe that the resonanceantiresonance separations are very large (about 200MHz) for this type of resonators (more than 3 times the values

Figure 6: Computed response of a thin film resonators using lithium tantalate

On figure 7 , we have represented the computed response of a four poles filter made with thin film resonators of figure 6 . The equivalent scheme of the resonators were computed with the same model of composite resonators as that used to compute the response given in figure 6 . We have used the data of table 2 and the dimensions given in figure 7. The filter was synthetized to have a $100 \mathrm{MHz}$ bandwidth with a Jaumann structure, it was considered that the resonators could be adjusted to the required frequencies by variation of the thickness of one electrode.

On the whole, this filter technology appears to be extremely promising for the applications to UHF filtering in the mobile communication systems, particularly with the use of high coupling, thermally stable materials. Further research work is required concerning the materials, the modelization of thin film resonators, and the filter architectures best adapted to integration and to the different requirements encountered in the radio subobserved for zinc oxide or aluminium nitride). The maximum realisable bandwidth is of the same order of magnitude as this resonance anti-resonance distance.

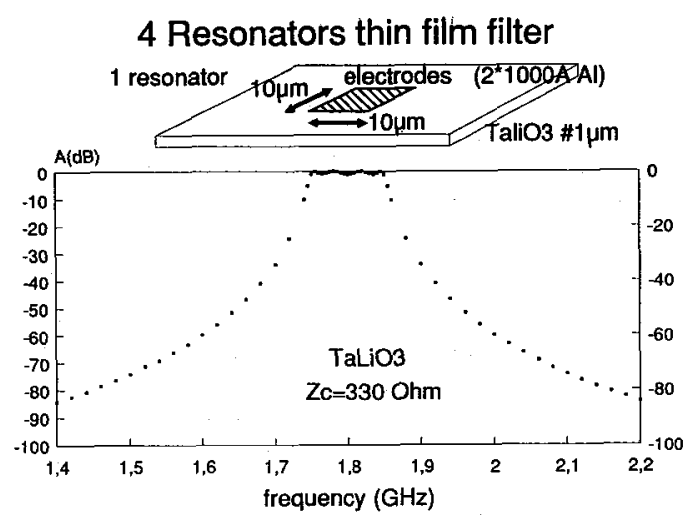

Figure 7: Computed response of a thin TFR filter having system. 


\subsection{UHF SAW filters.}

Important progress of the performances of low losses UHF surface acoustic waves filters were recently observed for $800-900 \mathrm{MHz}$ applications (A\#2dB). They have mostly resulted of important research efforts made in Europe, USA and Japan, in the last five years. This effort has led to the adoption of new filter architectures (group type filters, new resonator filters, etc...) and to important progress in the conception methods [8][9]. At 900MHz, the use of SAW filters for post-modulation and pre-mixing filtering is becoming the usual solution. At UHF, the SAW filters are naturally small (a very few $\mathrm{mm}^{2}$ at $900 \mathrm{MHz}$ ), they can present interesting out of band rejections $(40-50 \mathrm{~dB})$ that can probably be further improved. It was demonstrated that they can withstand an appreciable level of power (1 Watt) [9]. These filters are obtained using simple (1 mask level), batch processing techniques on large wafers of piezo-electric materials and hence are low cost devices. Lithium tantalate is the most commonly used material, it presents very low acoustic losses but presents a non negligible temperature coefficient.

Here again, there is presently no two $\mathrm{GHz}$ filters with sufficiently low losses, the best results being of the order of $3.5 \mathrm{~dB}$ near $1.8 \mathrm{GHz}$ and of $6 \mathrm{~dB}$ at $2.5 \mathrm{GHz}$. Several points will be more critical at $2 \mathrm{GHz}$ than at $900 \mathrm{MHz}$ in the development of low loss SAW filters; among them are the acoustic dissipation in the piezo-electric material and the ohmic losses in the electrodes. They will probably induce the choice of new solutions. For the materials, beside lithium tantalate, two recent ones, possessing zero temperature coefficient orientations, may be very interesting due either to a large acoustic velocity (lithium tetraborate (LBO)) [10] and/or to very reduced acoustic losses (lanthanum silico-gallate (LGS)) [11] [see table 3 ]. However, in this very important field, the advent of a low loss, very highly piezo-electric material, like lithium niobate, but being thermally compensated, remains very desirable. There is a reasonable hope that such a material can be found among the analogs of LGS. Here also, the advent of room temperature superconductors, may be very helpful for the electrodes.

A half micron technology will be required for the elaboration of the $2 \mathrm{GHz}$ filters. Since the relative bandwidth will be much larger than those presently considered at $900 \mathrm{MHz}$, new studies concerning the filter architecture and design are also required to obtain filter with the appropriate width and losses.

\section{INTERMEDIATE FREQUENCY FILTERS.}

The channel width is $200 \mathrm{kHz}$ for the GSM and the DCS 1800 ; the values of the intermediate frequencies (I.F.) are generally situated in the range 70 to $175 \mathrm{MHz}$ for the GSM, they will probably be in the range 150 to $350 \mathrm{MHz}$ for the DCS 1800 . The possible technologies for GSM and DCS $1800 \mathrm{IF}$ filters are quite numerous, but due to the small value of the relative bandwidth, all use piezo-electric solution (either bulk wave or surface waves). these technologies and their domains of application are represented in figure 8.

For the UMTS, in a TDMA scheme, one could envisage DECT or GSM type channels (respectively of the order of 1000 and $200 \mathrm{kHz}$ ) that could have to be implemented simultaneously at least in certain equipments. In a CDMA scheme, multiple values like 1, 5, 10, $20 \mathrm{MHz}$ (commutable in most cases) are envisaged.

Due to the frequency distance between the two sub-bands, the first intermediate frequency of the equipments will probably be situated in the range 190 to 350 MHz. These values are quite high for the smallest bandwidths $(\mathrm{BW})$ cited. The existence of such very small value of the relative BW (of the order of 1 thousandth), will constrain to the use of materials having very low temperature coefficients. This results of the fact that the frequency shift of the response curve admitted under the effect of temperature have most often to be specified as a very small fraction of the corresponding bandwidth (to minimize the losses of the spectral resource). Equally, this small relative bandwidth imply the use of a low loss material to obtain a good amplitude response (insersion losses and shape at the comer of the pass-band). Materials for Intermediate Frequency Filters

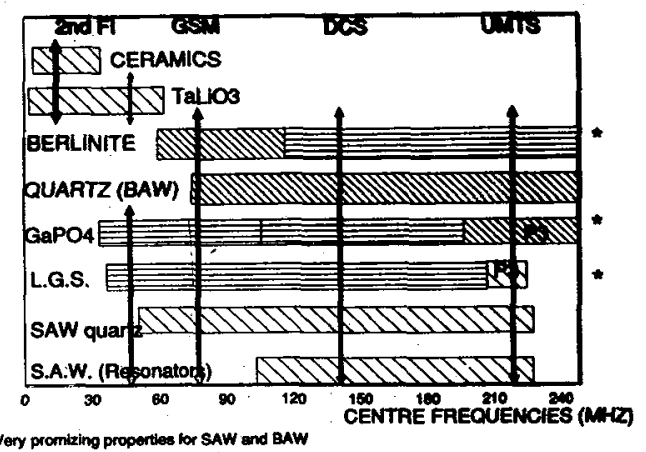

Figure 8: IF filters for GSM and DCS 1800. 
To optimize the size and cost of the equipment, a very desirable feature, in the TDMA hypothesis, will be to obtain two commutable bandwidths from the same circuit in re-utilizing most of the components. In the case of the CDMA hypothesis, the same question appears to be more difficult since the same filter technology may not be optimal for so different relative bandwidths; in this case, still more innovative solutions are to be found.

For the amplitude response of the filters, low insertion losses are desirable (typically 4 to $8 \mathrm{~dB}$ ) to permit to have a gain in preceding stages (LNA and mixer) giving the best compromize between the noise factor and the level of interferences generated by intermodulation distorsion when high level unwanted signals are present. It is also very interesting to place nearly all the selectivity required for the channel filtering in the first I.F. filter since this situation is the most favourable to minimize the interferences produced by intermodulation in the I.F. amplifier by signals situated near the channel. So that, to increase the receiver performances in a system that is planed to have a much greater "density" of mobiles, it may be desirable to research filters more selective than those presently used in most of the first generation of digital systems. The possibility to increase largely the selectivity exists and is already employed in the stations and also in the mobiles of some systems. The phase response has to be kept very nearly linear (constant group delay) on the parts of the bandwidth containing most of the energy of the useful signal.

Two main technologies of filters can be used in this frequency range: the SAW filter and the Bulk Acoustic Wave (BAW) filters. Traditionally, the first one are considered as more convenient when large bandwidths and linear phase responses are required while the second are viewed as being most adapted for the cases of small relative bandwidth and when reduced insertion losses are searched for. These views are now to be largely reconsidered, since the evolutions of both techniques and the advent of new materials have largely extend their domains of applications (towards higher frequencies and larger bandwidth for BAW filters and towards the small relative bandwidth and the low insertion losses for the SAW filters). Moreover, for low losses I.F. filters, a convergence of the type of response obtained from both type of filter is presently observed. So that, for applications at the horizon of 2002 , it will probably be wise to consider in depth all the constrains of the application and all the possibilities and potentialities of the two technologies. The mixing of both technologies in the same equipment is even of a probable occurrence in some hypothesis.

\subsection{SAW filters.}

The most usual solution for the mobiles and portables of the GSM is to use SAW devices for I.F. filtering. For this application many works were, in the five last years, devoted to enhance their characteristics (Shape factors, insertions losses, out of band rejections, dimensions), and several satisfactory compromises (with respects to the present specifications) were found. The researches are still going on and new devices will appear in the next generations of GSM equipments. As an example of this fact, figure $9 \mathrm{a}$ and $9 \mathrm{~b}$ indicate the principle and the frequency response of a filter using the new principle, recently found, of partial internal reflexions which constitute one of the most advanced solution found for the GSM SAW filters [12]. On the same figure $9 \mathrm{~b}$, the response of an already very good but more conventional and larger low loss filter using single phase unidirectional transducers is represented (dashed line). Recently the trend to use filters of the resonator type or intermediate between conventional transversal filters and resonator filters has appeared which may lead to very interesting solutions at the highest intermediate frequencies. Nearly all SAW IF filters for the GSM are made using ST cut quartz.
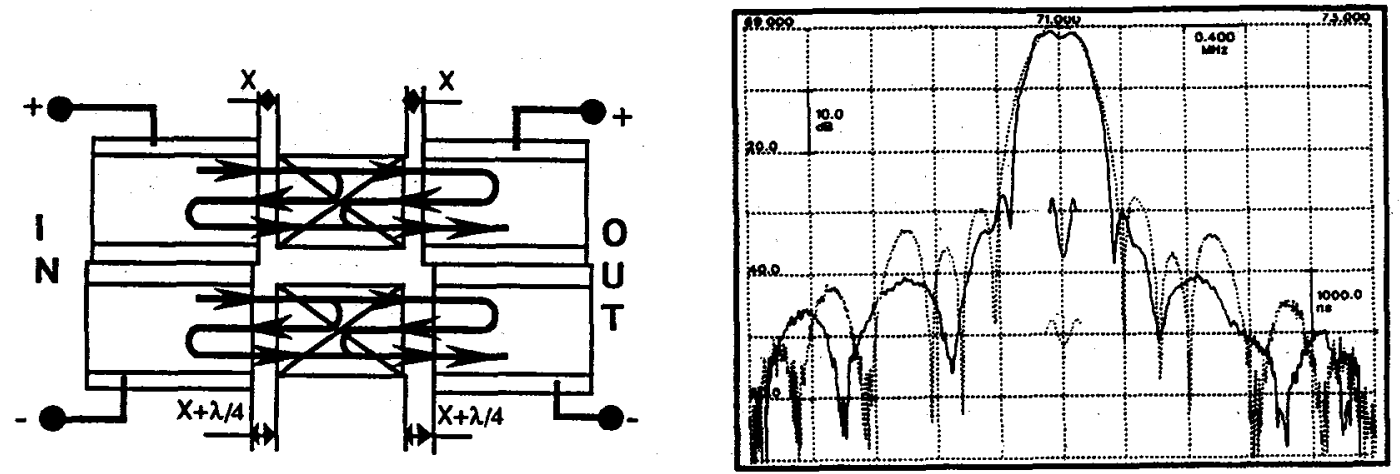

Figure 9: Principle (9a) and frequency response (9b) of a filter based upon a new principle. 
For the UTMS, the different values of the relative BW, of the centre frequencies and mostly, the requirement of reducing greatly the dimensions of the filters while finding multi-bandwidth filters, will conduct to research further evolutions. The use of new materials may offer important new possibilities for the obtainment of better solutions. Particularly, for the larger bandwidth, it will be very advantageous to use a material presenting simultaneously a larger coupling coefficient than ST quartz and a good thermal behaviour. Moreover, to obtain smaller devices, it can be extremely useful to consider the material giving low acoustic velocity. In all cases, the high value of the centre frequency will favour the most thermally stable materials. On table 3 , we have indicated the properties of the materials that can be interesting to obtain the different types of filters.

In this table, their is several new and much probably extremely interesting materials for which all the SAW propagation properties are presently not accurately determined. Although, it is possible to notice that the quartz like materials (quartz, $\mathrm{AlPO}_{4}, \mathrm{GaPO}_{4}$ ) have from far the best thermal behaviour.

Table 3: Materials for SAW filters

\begin{tabular}{|c|c|c|c|c|}
\hline MATERIAL & $\mathrm{k}^{2}(\%)$ & $\begin{array}{l}\text { Relative shift } \\
\text { for } 100^{\circ} \mathrm{C}\end{array}$ & $\begin{array}{l}\text { Thermal Shift (kHz) } \\
\text { at } 225 \mathrm{MHz}\end{array}$ & $\begin{array}{l}\text { Max.BandW: } \\
\text { at 225MHz }\end{array}$ \\
\hline $\begin{array}{l}\text { Quartz ** } \\
\text { (ST cut) }\end{array}$ & $\begin{array}{r}0.14 \\
\mathrm{dv} / \mathrm{v} \\
0.058^{*}\end{array}$ & $9010^{-6}$ & 20 & $* * *$ \\
\hline $\begin{array}{l}\mathrm{AlPO}_{4} \\
\text { ( } \mathrm{ST} \text { cut) }\end{array}$ & $\mathrm{dv} / \mathrm{v}=0.245^{*}$ & $\begin{array}{l}\text { very small? } \\
100-150.10^{-6} ?\end{array}$ & $25 ?$ & $* * *$ \\
\hline $\begin{array}{l}\mathrm{GaPO}_{4} \\
\left(\mathrm{ST} \text { cut }^{*}\right)\end{array}$ & $\mathrm{dv} / \mathrm{v}=0.146$ & $\begin{array}{l}\text { small } \\
12510^{-6}\end{array}$ & 28 & $* * *$ \\
\hline $\begin{array}{l}\mathrm{La}_{3} \mathrm{Ga}_{5} \mathrm{SiO}_{14} \\
\text { \& analogs }\end{array}$ & 0.5? to much greater? & $\begin{array}{l}\text { quite small? } \\
100-20010^{-6} ?\end{array}$ & $?$ & $* * *$ \\
\hline $\mathrm{Li}_{2} \mathrm{~B}_{4} \mathrm{O}_{7}$ & $\begin{array}{r}>0.8 ? \\
* *\end{array}$ & $.50-1.010^{-3}$ & $112-225$ & $* * *$ \\
\hline TaliO $_{3}$ & $\begin{array}{r}1.3-1.5 \\
* *\end{array}$ & $2.40010^{-3}$ & 540. & $\begin{array}{r}* * * \\
>15 \mathrm{MHz}\end{array}$ \\
\hline $\begin{array}{l}\mathrm{LiNbO}_{3} \\
\text { (coupe Y) }\end{array}$ & $\begin{array}{r}4,8-5.57 \\
* *\end{array}$ & $7.2-9.410^{-3}$ & 1900. & $\begin{array}{r}* * * \\
>25 \mathrm{MHz}\end{array}$ \\
\hline
\end{tabular}

* from Wallnöfer et al. [13], **Large wafers available

***max. bandwidth and insertion losses are not independent, they are also very dependant on the type of design used.

Among them, berlinite $\left(\mathrm{AlPO}_{4}\right)$ appears to be extremely interesting for VHF SAW filters having relative bandwidth up to about 5\% due to the large value of its coupling coefficient [13] and to a smaller value of the acoustic velocity. The existence of crystalline orientations leading to better temperature coefficients than for quartz seems possible. The SAW properties of $\mathrm{La}_{3} \mathrm{Ga}_{5} \mathrm{SiO}_{14}$ (LGS), which is also a material belonging to the crystal class of quartz, are not presently available but the bulk acoustic wave properties [14] indicate the high probability of large coupling coefficients, reduced velocities and a good thermal behaviour. Several analogs of LGS are presently being studied, it is already known that they will present much larger coupling coefficients [11] and similar velocities than LGS. These materials may be very interesting for the larger bandwidth.

On the whole it appears that, in any hypothesis, further works are required either on filter architecture, filter design methods and on new materials. These latter are probably the key points to find much better solutions and, it seems important to determine accurately their constants and temperature coefficients, to compute also accurately their SAW properties and to further develop those presenting the most interesting properties for the applications. Researches about still more advanced solutions, for example, those permitting a co-integration with semiconductors by the obtainment of low losses films of high coupling, thermally stable piezoelectric materials on $\mathrm{Si}, \mathrm{GaAs}$, etc..., have probably to be started now.

\subsection{BAW I.F. filters:}

BAW filter were traditionally used for IF filtering in analogic radiocommunication equipments making use of FDMA, since this application require extremely selective filters at a quite low frequency ( filters at 21.4 or 45 
$\mathrm{MHz}$ having typically a 8 to 10 poles polynomial response giving very high shape factors and ultimate out of band rejection under $100 \mathrm{~dB}$ ). Technological progress (ion beam etching, direct to frequency plating, etc..) have, in the ten past years, extended the domain of applications of bulk wave filters to the very high frequencies and then to the ultra high frequencies [15]. More recently progress in synthesis have allowed to obtain phase responses compatible with digital transmission, very similar to what is presently obtained with low losses SAW filters. In the same time, the advent of several new materials have greatly increased the possibilities to obtain much larger bandwidth while keeping the advantage of a high thermal stability [14][16][17]. The new possibilities bring by the high coupling analogs of quartz are illustrated in figure 10 which represents the electrical response of a AT AlPO ${ }_{4}$ resonator (please note the much larger resonance anti-resonance distance than in quartz at the same frequency). Another illustration is given in figure 11 where the responses achievable under certain hypothesis [18 ] for 4 pole filters using quartz, $\mathrm{AlPO}_{4}$ and $\mathrm{GaPO}_{4}$ are compared. The thermal stability of two of the recent materials is illustrated on figure 13 (AT cut of berlinite $\left(\mathrm{AlPO}_{4}\right)$ ) and on figure 12 (Y rotated compensated cut of LGS).

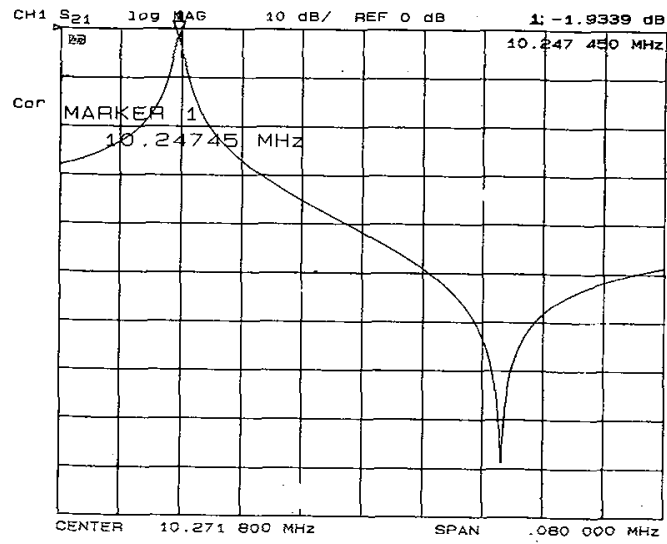

Figure 10: Response of an $\mathrm{AlPO}_{4}$ resonator.

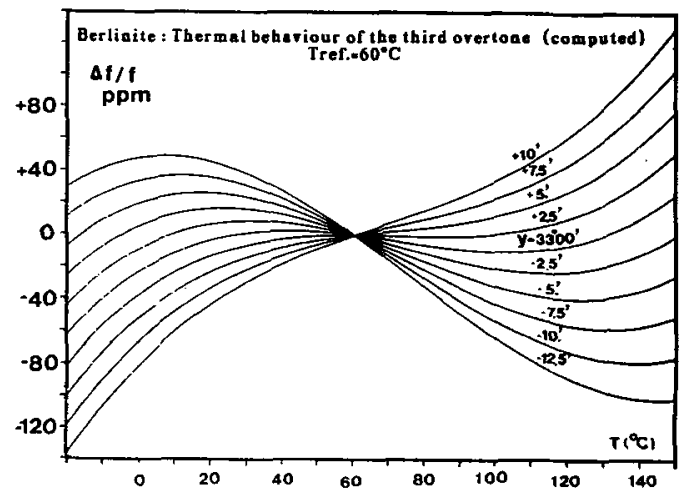

Figure 12: Thermal behaviour of $\mathrm{AlPO}_{4}$
FILTRES JAUMANN 4 POLES Cheblshev 1 dB rippte, Rt=2000 Ohm. Center Frequency $20 \mathrm{MHz}$

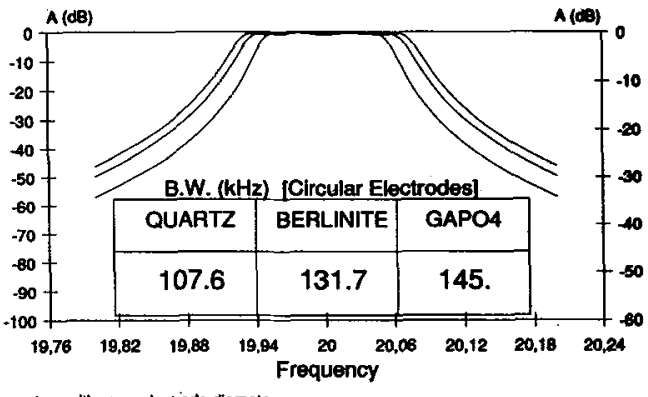

(Resonators wth max. etectrode diamete giving no symmetrical arthamonics)

Figure 11: Four pole filters using the analogs of quartz.

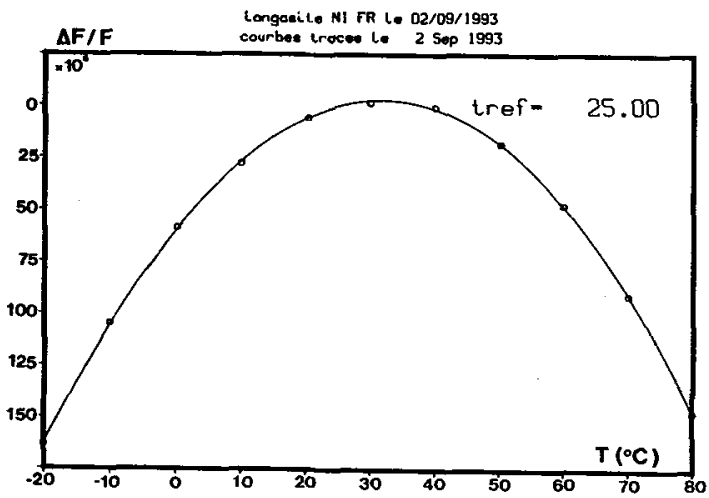

Figure 13: Thermal behaviour of LGS.

Several types of high performances BAW filters are presently used in the GSM base stations. Bulk wave filters are also used in the mobiles of several non European digital systems. The high performances possible with bulk wave filters are illustrated on figure 14 and 15 which represent the responses of industrial filters for GSM and DCS 1800 applications (Courtesy of Thomson-CEPE). We can notice the reduced insertion losses $(4,6 \mathrm{~dB}$ for the $71 \mathrm{MHz}$ filter of figure 14 and $3.55 \mathrm{~dB}$ for the $211 \mathrm{MHz}$ filter of figure 15), the excellent shape factors, and the very large out of band rejections.

A recent, and important progress in the field of VHF bulk wave devices, is the discovery of very efficient chemical methods permitting the obtainment at low cost of large quantities of VHF plates [19]. Such processes exist 
presently for quartz and berlinite, they may be extended to gallium phosphate and to LGS without many difficulties.

The interest of bulk wave filters for the next generations of radiocommunication equipments and particularly for the UTMS rely principally on the following facts:

-The VHF I.F. filters are very small (\#.5 to $1 \mathrm{~mm} 2 /$ pole at $200 \mathrm{MHz}$ ).

-Very selective responses can be obtained.

-BAW filters have extremely good thermal behaviours.

-Collective technologies are possible (see $\$ 4.2 .1$ )

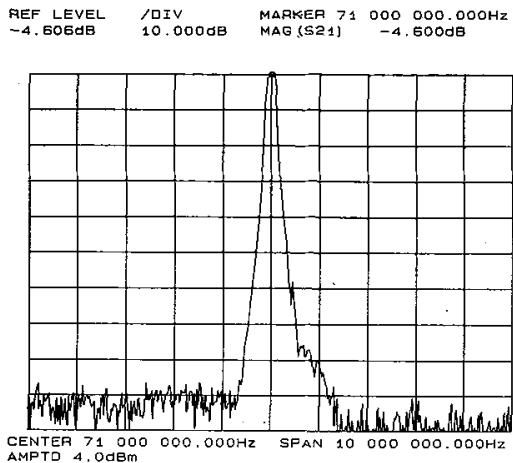

Figure 14: Response of an industrial $71 \mathrm{MHz}$ bulk wave filter [20].

The largest relative bandwidth achievable with bulk wave filters using the temperature compensated material (lithium tantalate) having the highest coupling coefficient is of about $7.5 \%$, but the same material cannot, nowa-day give very satisfactory filters for relative BW below about $.5 \%$. The most important properties of the presently known materials that can be of interest for the UMTS I.F. filters are listed in table 4.

Table 4: Properties of materials for BAW filter applications.

\begin{tabular}{|c|c|c|c|c|}
\hline MATERIAL & $\mathrm{k}(\%)$ & $\begin{array}{c}\Delta f / f \\
-25^{\circ} \text { to }+75^{\circ} \mathrm{C}\end{array}$ & $\begin{array}{l}\text { Thermal Shift (kHz) } \\
\text { at } 225 \mathrm{MHz}\end{array}$ & $\begin{array}{l}\text { Max. practical } \\
\text { bandW. at } 225 \mathrm{MHz}^{*}\end{array}$ \\
\hline $\begin{array}{l}\text { Quartz** } \\
\text { (AT cut) }\end{array}$ & 8. & $12.10^{-6}$. & 2,7 & $500 . \mathrm{kHz}$ \\
\hline $\begin{array}{l}\mathrm{AlPO}_{4} \\
\text { (AT cut) }\end{array}$ & 11 & $20.10^{-6}$ & 4.5 & $1100 . \mathrm{kHz}$ \\
\hline $\begin{array}{c}\mathbf{G a P O}_{4} \\
\text { (AT cut) }\end{array}$ & 16 & $<40.10^{-6}$ & $<9.0$ & $\begin{array}{l}2300 . \mathrm{kHz} \\
\text { ov. } 30 \mathrm{OK} 200 \mathrm{kHz}\end{array}$ \\
\hline $\begin{array}{l}\mathrm{La}_{3} \mathrm{Ga}_{5} \mathrm{SiO}_{14}{ }^{* *} \\
\& \operatorname{analogs}(* *)\end{array}$ & $\begin{array}{l}15 \text { to } \\
30 ?\end{array}$ & $\begin{array}{l}100 ? \text { to } \\
150.10^{-6}\end{array}$ & $22.5 ?-33.75$ & $\begin{array}{l}1900 . \mathrm{kHz} \\
\text { ov.3 OK } 200 \mathrm{kHz}\end{array}$ \\
\hline $\mathrm{Li}_{2} \mathrm{~B}_{4} \mathrm{O}_{7}^{* *}$ & 23 & $\begin{array}{l}300 ? \text { to } \\
600.10^{-6}\end{array}$ & $\begin{array}{l}\text { too much } \\
\text { for TDMA }\end{array}$ & $\begin{array}{l}4800 . \mathrm{kHz} \\
\text { ov.3 OK } 200 \mathrm{kHz}\end{array}$ \\
\hline $\begin{array}{l}\text { TaliO3** } \\
\text { (X cut) }\end{array}$ & 45 & $600.10^{-6}$ & $\begin{array}{l}\text { too much } \\
\text { for TDMA }\end{array}$ & $>16 . \mathrm{MHz}$ \\
\hline
\end{tabular}

*The values indicated $4 k^{2} / \pi^{2}$

are some how conservative to consider stray capacitances, see also [18]. **Large wafers available.
Figure 15: Response of an industrial $211 \mathrm{MHz}$ bulk wave filter [20].

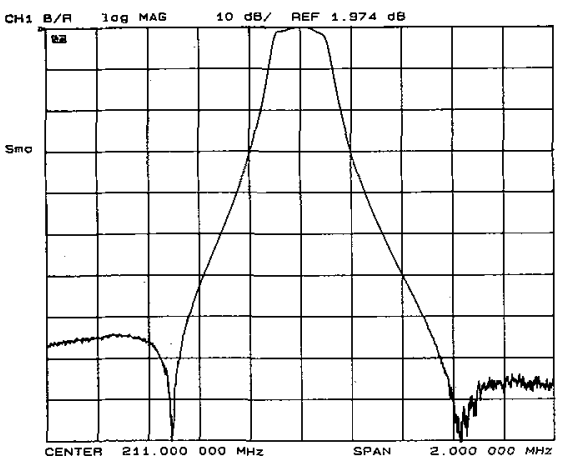


On table 4 we can notice again that the analogs of quartz present the most favourable temperature stability with a third order behaviour for quartz and berlinite, and most probably for gallium phosphate [21]. Again, the importance of the thermal behaviour that will play a very important role in the choice of material, is to be emphasized. This results, of the fact that there is a case where a small bandwidth will be used. This, in turn, will imply that the admissible frequency shift of the response of filters due to thermal effects has to be very small (see the begining of $\S 4$ ).

Most of the materials listed in table 4 can be used to obtain filters with a bandwidth near $200 \mathrm{kHz}$, but if the fundamental mode is to be used, the natural choice is quartz. If, as possible, economic reasons render the choice of the third overtone more interesting, then $\mathrm{GaPO}_{4}$ and LGS are a good choice. Three materials appear to be very interesting for the case of a near $1000 \mathrm{kHz}$ BW (AlPO, $\mathrm{GaPO}_{4}$, and LGS). In the case of commutable bandwidth $(200 / 1000 \mathrm{kHz})$, extra stray capacitances are to be taken into account so that the two materials with the largest coupling coefficients seem the best adapted $\left(\mathrm{GaPO}_{4}\right.$ et LGS). For bandwidth situated between 2 and $15 \mathrm{MHz}$ the high coupling analogs of LGS and lithium tantalate seem to be the most interesting (CDMA hypothesis).

Several new developments are required to obtain BAW IF filters with optimized design, a part of them must concem the design of the filters (geometry, sensitivity to dispersion, commutable bandwidth etc..) an other important part must be devoted to the development of materials (GaPO4, LGS and analogs). Other developments must also be made on the technological aspects.

\subsection{New technologies for bulk wave filters.}

Except for some rare cases concerning essentially miniaturized low frequency resonators, the bulk wave devices are presently elaborated individually on small plates. The very small size of VHF devices, the new possibilities offered by the recent polishing equipments that allow to obtain thin large wafer with a high degree of parallelism and the recent advances in chemical etching permit now to consider the obtainment of VHF BAW filters using batch processing techniques. This will constitute a very important new advance in the bulk wave technology and will lead to a large reduction of the cost of such devices. New developments will be required to set up such a technology concerning several process aspects, the design of the devices and the materials (large crystals are necessary to obtain wafers, a good crystalline quality is also required for chemical etching [22]). On figure 16, an example of a half of a filter made using the present advanced technology is represented. It concerns a small plate obtained by chemical etching containing 2 integrated resonators at $70 \mathrm{MHz}$ (half of a filter) [23]. At higher frequencies or with larger plates, the whole filter can be integrated on the same plate. Figure 16 is a sketch of what could be the tomorrow VHF filter technology. It may be observed that this technology remains quite simple and that wafers of 4 " diameter already exist for several materials.
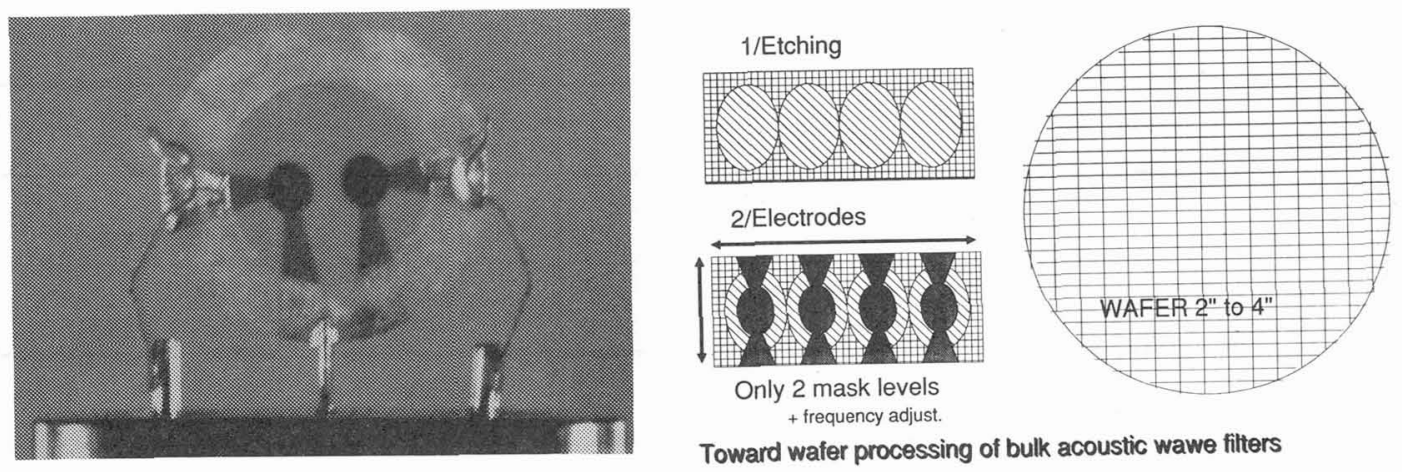

Figure 16: Filter made using the most advanced present Figure 17: A sketch of what could be the tomorrow techtechnology. nology

Recently, an other advance was proposed that consists in bonding quartz chips upon silicon chips surface, this method can very probably be extended to other piezo-electric materials and to other semiconductors and may have an interest for UHF or IF filters. 


\section{FREOUENCY SOURCES.}

The frequency control in the present mobiles for GSM (local synthesized oscillators and timing for the digital section) is presently made from a reference oscillator having a stability of the order of some $10^{-6}$. This crystal oscillator is most often a TCXO using an analog compensation of the temperature variations.

The increase of the frequencies and almost of the bauds rates will much probably require the use of a much higher stability (particularly in the case of CDMA with large chips rates). Two choices can be made: the first is to obtain this stability in the mobile using a more stable frequency source. The other choice is to synchronise the mobile on the stations by some method. In this case however, due to the multipath propagation and to the Doppler effect, a non negligible time of observation and a lot of computations will be required (depending of the needed stability) to achieve the frequency stability. Moreover in this case, the mobile oscillator has still to have an excellent short (or medium) term stability to interpolate between two observations. This frequency comparison can be made either in the mobiles or in the stations but requires always an exchange of data. In any cases, the phase noise of the reference oscillator of the mobiles has to be as reduced as possible.

The probable advent of low cost digital TCXO or of some other low cost method to increase greatly the frequency (and timing) stability in the mobiles may change in an important manner the conditions of this choice. However, in any cases there is a large interest to reduce the frequency aging of the resonators and to increase their $Q$ factors (phase noise) by using an improved material (quartz).

The oscillators used in base stations are very high performances OCXO whose characteristics are mainly determined by the needs of the interface with the fixed network. They use quartz resonators with state of the art performances ( aging, Q factors etc..), for which the quality of the material is determinant. New progress in the crystalline quality and purity of the material will be very interesting.

In nearly all cases the VCO of the frequency synthesizers use resonators (LC, DR,...). It will be very interesting to use high $Q$ factor miniature resonators similar to that discussed previously (TFR, SAW) for the filters and, if possible, to integrate them to obtain very small circuits for this function while obtaining better phase noise characteristics (resulting of the better $Q$ factor).

\section{SUMMARY.}

The performances of the radio interface of mobile systems equipments are very dependant on those of the filters and frequency sources. New characteristics and an important advance in the performances of the filters and oscillators will be required for the next generation of systems particularly for the UMTS. Due to the small volume required for the terminals, to a most probable large increase of their complexity, a reduction of the volume of the different functions of the radio-sub system is mandatory. For the electronics this will be achieved by a further integration. For the filters and frequency generation devices which will most probably be more numerous than in the equipment of the present digital systems, new solutions are to be found. Otherwise they will become a limiting factor in the miniaturization of the equipments.

In the review made of the different technologies for the different filters of the radio sub-system, it has appeared that several new technologies can give devices having simultaneously the required performances and very small dimensions. The case of the UHF thin film resonators filters which are co-integrable with semiconductors in mixed I.Cs is the most significative example. It was also observed that technologies commonly used at lower frequencies and for other bandwidth can be transposed for the new requirements, but with non negligible efforts in all cases.

In most case also, it was observed that these requirements concerning mainly the use of higher frequencies and larger bandwidth, will need the use of new piezo-electric materials having a larger coupling coefficient than quartz, a high thermal stability and very low high frequency acoustic losses. For the TFR filters the availability of thin piezo-electric films presenting similar properties is essential.

The discussion has revealed that most of the new piezo-electric materials presently studied $\left(\mathrm{AlPO}_{4}, \mathrm{GaPO}_{4}\right.$, LGS and its analogs, $\mathrm{Li}_{2} \mathrm{~B}_{4} \mathrm{O}_{7}$, etc..) and presented at the European Workshop on Piezoelectric Materials may be of interest for at least one application in the future radio-communication equipments. For the most recent materials, the developments must be pursued up to the obtainment of large crystals of high crystalline quality. Further developments in the perfection of quartz synthetic crystals, permitting to improve the long term stabilities of the oscillators and to enhance their phase noise properties are also very desirable. 
The recent advances in the very high frequency BAW filters technology, give new openings to obtain very small devices with high performances. They give also, the very desirable possibility of further evolutions towards the low cost batch production methods already employed for SAW filters.

We believe that most of the trends observed for the devices destined to applications in the equipments of the next generation of mobile communication systems are very significative of the futures evolutions in piezoelectricity.

Acknowledgments: The authors wish to thank MM. N.Ruelle and M.Bon for helpful contributions in this study. They acknowledge fruitful discussions with many colleagues at CNET on the components for Radio-Mobile Systems. They thank MM. Arnaud, Buisson, Capelle, Cochet-Muchy, Marechal, Michel, Philippot, Solal and Zarka for their contributions to the material science aspects of this study.

\section{References:}

[1] Charbonnier A., Hubert J., Attal J.,Cohen M., Evoi C.; Commutation \& Transmission n spécial "Communication avec les mobiles" 1993 p.109-121.

[2] Margat C., Attal J., Damblin J.L., Desplanque J., Fino B., Lompech M.N.; Commutation \& Transmission $\mathbf{n}^{\circ}$ spécial "Communication avec les mobiles" 1993 p.7-20.

[3] Anemogiannis K.,Berek S., Zottl H.; Proceedings of the 1990 IEEE Ultrasonics Symposium p.129-133

[4] Burns S.G., R.J.Weber R.J., Braymen S.D., Proceedings of the 45th Annual Symposium on Frequency Control 1991 p.207-211.

[5] Cushman D., Lau K.F. Garber E.M., Mai K.A., Oki A.K, Kobayashi K.W. Proceedings of the 1990 IEEE Ultrasonics Symposium p.519-524.

[6] Vale C., Rosenbaum J., Horwitz S., Krishnaswamy S., Moore R.; Proceedings of the 44th Annual Symposium on Frequency Control 1991 p.332-336

[7] J.M. Haussonne France Telecom CNET, Personal communication

[8] Ruppel C.C.W, Dill R., Fisherauer A., Fisherauer G., Gawlik W., Müller F., Reindl L., Ruile W., Scholl G., Schrop I., Wagner K.Ch.; IEEE trans. Ultrason. Ferroel.Freq.Control 1993 V.40, n5 p. 438-450.

[9] Hikita M., Shibagaki N., Tabuchi T., Akagi T.; Electronics letters 1993 v. 29 n7 p.631-632.

[10] Adachi M., Shiosaki T., Kobayashi H., Ohnishi O., Kawabata A.; Proceedings of the 1985 IEEE Ultrasonics Symposium p.228-232

[11] Sakharov S.A., Larionov I.M., Medvedev A.V.; Proceedings of the 1992 IEEE Frequency Control Symposium June 1992 p.713-723.

[12] Solal M., Hodé J.M.; Proceedings of the 7th. European Frequency and Time Forum Neuchâtel 16-18 march 1993 p.499-503

[13]W.Wallnöfer, J.Stadler, P.Krempl; Proc.7th. European Frequency and Time Forum Neuchatel 16-18 march 1993 p.653-657.

[14] Silvestrova I.M., Pizaresky Yu.V., Bezdelkin V.V., Senyushenkov P.A.; Proceedings of the 1993 IEEE Frequency Control Symposium p.351-352

[15] Brauge J., Fragneau M., Aubry J.P. Proceedings of the 39th Annual Symposium on Frequency Control 1985 p.504-513.

[16] Detaint J., Carru H., Schwarzel J., Joly C., Capelle B., Zarka A.,Zheng Y., Proceedings of the 45th Annual Symposium on Frequency Control 1991 p.166-180.

[17] Detaint J., Lançon R. Proceeding of the 30th Annual Frequency Control Symposium 1976 p.132-140

[18] Detaint J., Schwartzel J., Joly J., Capelle B., Zarka B., Zheng Y., Toudic Y., Philippot E.; Proceedings of the 6th European Frequency and Time Forum Noordwijk 1992 p.223-227.

[19] E.Philippot, A.Ibanez, A.Goiffon, B.Capelle, A.Zarka, J.Schwartzel, J.Detaint; Proceedings of the 6th European Frequency and Time Forum Noordwijk 1992 p.383-388.

[20] Filters constructed by Thomson-CEPE France.

[21] Deleuze A., Goiffon A. Ibanez A., Philippot E.; Proceedings of the 1993 IEEE Frequency Control Symposium Salt Lake City p.381-389

[22] A.Zarka A., Capelle B., Zheng Y., Schwartzel J., Détaint J., Buisson X., Toudic Y. Proceedings of the 1993 IEEE Frequency Control Symposium p.696-706.

[23] Détaint J., Schwartzel J., A.Zarka A., Capelle B., Joly C. Proceedings of the 7th. European Frequency and Time Forum Neuchâtel 16-18 march 1993 p.561-566 